\title{
Social structure of a population of bottlenose dolphins (Tursiops truncatus) in the oceanic archipelago of Madeira, Portugal
}

\author{
ANA DINIS ${ }^{1,2,3}$, FILIPE ALVES ${ }^{1,3}$, CÁTIA NICOLAU ${ }^{1}$, CLÁUdiA RIBEIRO ${ }^{1,3}$, MANFRED KAUFMANN ${ }^{2,3}$, \\ ANA CANADAS ${ }^{4}$ AND LUÍ́s FREITAS ${ }^{1,3}$ \\ ${ }^{1}$ Madeira Whale Museum, Caniçal, Madeira, Portugal, ${ }^{2}$ University of Madeira, Faculty of Life Sciences, Madeira, Portugal, ${ }^{3} \mathrm{CIIMAR} /$ \\ CIIMAR-Madeira, Interdisciplinary Centre of Marine and Environmental Research of Madeira, Edifício Madeira Tecnopolo, \\ 9020-105, Funchal, Portugal, ${ }^{4}$ ALNILAM - Research and Conservation, Madrid, Spain
}

\begin{abstract}
In order to investigate social structure, 11 years of individual photo-identification data of bottlenose dolphin were analysed. We examined the type of association indices between pairs of identified individuals; the patterns of affiliation between individual dolphins and the probabilities of association between individuals over time. Between 2001 and 2012, there were 272 encounters which resulted in the identification of 501 individuals. The discovery curve resulting from the photo-identification analysis indicated an open population with regular recruitment of new individuals. All individuals were found to be associated at an association index of $<0.05$. A total of 291 individuals recorded from 2004 to 2012 were used to assess the temporal pattern of the social structure. The model fit to the Standardized Lagged Association Rate (SLAR) that best described the studied bottlenose dolphin population was 'casual acquaintances', and the analysis of associations over time showed a decreasing SLAR curve that falls until reaching the null rate, confirming random associations. The decline of the SLAR curve after $\sim 500$ days (1.4 years) suggests disassociation over that time period which can be explained by demographic events such as mortality or emigration. In an open ocean habitat like Madeira this is not unexpected, as there are neither geographic boundaries nor enclosed environments. This population presented a dynamic and fluctuating social structure, where groups change in size and composition. In future conservation efforts this population should be considered as one large community, where individuals associate, disassociate and reassociate with each other over time.
\end{abstract}

Keywords: bottlenose dolphins, photo-identification, associations, fission-fusion, NE Atlantic

Submitted 4 December 2014; accepted 4 April 2017; first published online 30 May 2017

\section{INTRODUCTION}

One of the most important attributes of any animal population is its social structure (Whitehead, 2009). This is often a key element of the population biology of a species, influencing processes such as gene flows or spatial distribution patterns (Wilson, 1975). Mammals have complex social structures; these may vary considerably through time, both between and within species. Therefore, describing and classifying those structures is complex and challenging (Costa \& Fitzgerald, 1996). Knowledge regarding the identity of the interacting, associating or grouped animals is essential for social structure studies (Whitehead \& Van Parijs, 2010). These types of studies are based on the identification of individual animals and on recording their interactions (Whitehead, 2008). One of the best methods to achieve this is using photo-identification (photo-id). Photo-id is based on the repeated recognition of individuals through photographs and has become an essential technique to provide information on group stability and association patterns

Corresponding author:

A. Dinis

Email: ana.dinis@ciimarmadeira.org
(Würsig \& Würsig, 1977). Photographing certain body parts is a non-invasive method of identifying and monitoring individuals over time. Bottlenose dolphins (Tursiops truncatus), as well as other dolphin species can be individually identified using photo-id of their dorsal fins (Würsig \& Jefferson, 1990). Each individual has a distinct and unique contour of the fin as a consequence of the interactions with conspecifics, environmental or anthropogenic factors. Thus, the posterior edge of the dolphin's dorsal fin may become irregular, resulting in recognizable patterns of notches and scars (Würsig \& Jefferson, 1990).

Based on genetic information, Quérouil et al. (2007) suggest that there is a single population of bottlenose dolphins in the pelagic waters of the North-east Atlantic, which is not significantly differentiated from the pelagic population of the North-west Atlantic. Madeira archipelago is one of the most isolated oceanic habitats in the North-east Atlantic; thus it may be expected to find a greater differentiation in the population structure. However, dolphins are capable of travelling large distances in short periods (Wells et al., 1999), making it possible that the lack of geographic structuring is explained by large home ranges and/or high dispersal in the study area (Quérouil et al., 2007). In terms of genetic structure the bottlenose dolphins in Madeira seem to be part of a bigger Atlantic pelagic population with high levels 
of gene flow (Quérouil et al., 2007). Strong site fidelity, with the presence of both resident groups and resource specialization, as a consequence of different social and behavioural strategies, could be leading factors for a differentiation of genetic structure (Hoelzel et al., 1998). Therefore, the social structure is sensitive to the genetic population structure (Whitehead \& Van Parijs, 2010).

Previous studies on bottlenose dolphins describe them as living in a so-called fission-fusion community, where individuals associate in small groups that change in composition, often on a daily or even hourly basis (Würsig \& Würsig, 1977; Wells et al., 1987). Unlike animals that live in groups of constant composition, social relationships in a fission-fusion society may depend strongly on 'who is there and who is not' (Connor et al., 2000). Several studies (e.g. Wells, 1991; Smolker et al., 1992; Wilson, 1995) reported a great variability in social strategies within and between populations, such as different gender-related bonds that could be due to differences in predation risk, mating and availability or use of resources. In Florida, patterns of social association facilitate the partitioning of continuously distributed resident dolphins into geographic management units (Wells, 1986). The frequency of associations between individuals that inhabit overlapping or adjacent ranges can help to define population units. Given that this information is geo-referenced, the definition of management units makes it possible to relate specific threats to a particular population or community, allowing the assessment of potential impacts and mitigation efforts (Connor et al., 2000).

In order to investigate the social structure of the bottlenose dolphin population that occurs in the oceanic archipelago of Madeira, individual photo-id data collected during 11 years were analysed. Information on social structure is important for management and conservation plans for this species in the study area, as different social units may require individual management strategies.

\section{MATERIALS AND METHDDS}

\section{Study area}

The Madeira archipelago is located in the North-east Atlantic $\left(32^{\circ} \mathrm{N} 17^{\circ} \mathrm{W}\right)$ at $\sim 670 \mathrm{~km}$ west of Morocco. It is formed of two main volcanic islands, Madeira and Porto Santo, separated by a stretch of $\sim 50 \mathrm{~km}$. It comprises also two subarchipelagos: the Desertas Islands, located $\sim 20 \mathrm{~km}$ south-east, and the Selvagens Islands located $300 \mathrm{~km}$ south of Madeira Island. Madeira and Porto Santo are inhabited, whereas Desertas and Selvagens are uninhabited natural reserves (Caldeira \& Sangrá, 2012). These oceanic volcanic islands have a reduced continental shelf, which results in deep waters and submarine canyons just a few miles offshore (Geldmacher et al., 2000), reaching depths of $3000 \mathrm{~m}$. Data were recorded from boat surveys around the islands of Madeira, Desertas and Porto Santo. The study area covered $4818 \mathrm{~km}^{2}$ up to $20 \mathrm{~km}$ offshore (Figure 1 ).

\section{Data collection}

Photographs were taken on year-round systematic and nonsystematic research boat surveys, as well as from whalewatching boats. One hundred and seventeen systematic surveys were carried out following predetermined line-

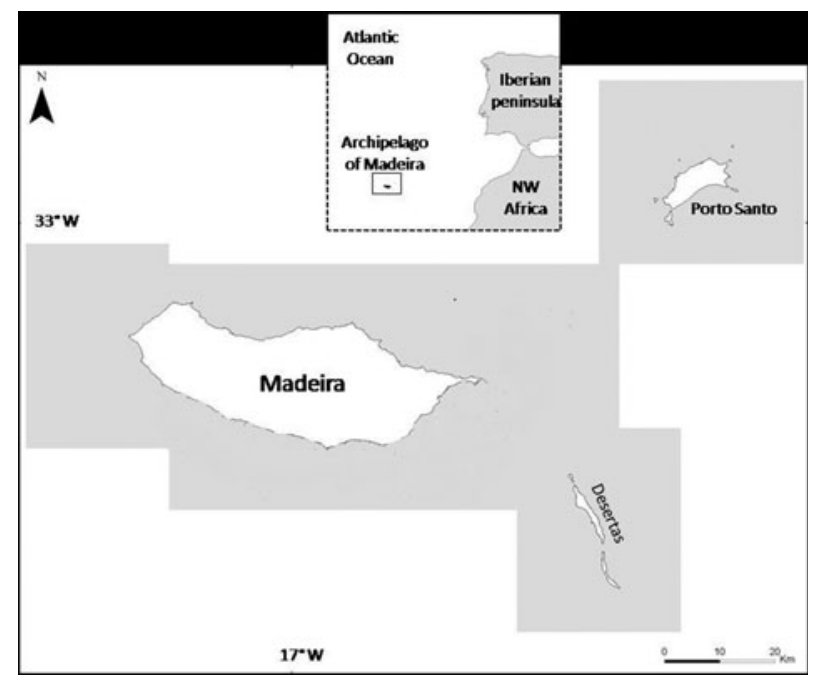

Fig. 1. Map showing Madeira archipelago and its islands, located in the North-east Atlantic (inset), and the main study area with the survey area in grey. Selvagens Islands not shown. (Adapted from Alves et al., 2013.)

transects. Surveys were carried out between 2001-2002 and 2004, and from 2007 to 2012. Additionally, one hundred and eighty-four non-systematic surveys were carried out between 2004 and 2012 (Figure 2). Sighting data (GPS position, initial time, best group size estimation and group composition), weather and effort information were recorded. Effort was conducted during daylight hours at Beaufort Seastate $\leq 3$. During systematic surveys, sometimes the time available constrained the data collection of individual photographs of the entire group; as such the photographic coverage and identification of all the individuals present in the group was not always assured (for details on these surveys see Alves et al., 2013). In this study, the term 'group' was used as the sampling unit and defined as all dolphins sighted within a $100 \mathrm{~m}$ radius from each other (Wells et al., 1987). Dolphins were classified into three categories - adults, subadults and calves according to their size, colour and behaviour. The adult class corresponded to large and robust animals. Calves were identified due to their small body size and permanent association with an adult (Mann et al., 2000). The individuals with body size smaller than the adults and that were independent from an adult animal were considered subadults (Wells et al., 1987). Photographs were taken using digital cameras (Nikon $\mathrm{D}_{2} \mathrm{H}$ and $\mathrm{D}_{700}$ ) equipped with Nikkor zoom lenses ranging between 70-400 $\mathrm{mm}$ in both systematic and random surveys.

Digital photographs from different whale watching boats were also analysed. These images were obtained from 2003 to 2012 in the south coast of Madeira Island. These opportunistic platforms operate year-round, with $1-3$ daily trips, with no specific target species. The photographs were taken whenever bottlenose dolphins were sighted by trained observers onboard, as well by experienced skippers.

\section{Photo-identification}

A photo-id catalogue was compiled. A dataset of capture histories was created using individual information taken from the photographs (following Würsig \& Jefferson, 1990). An individual identification within an encounter was defined as a 'capture'. 

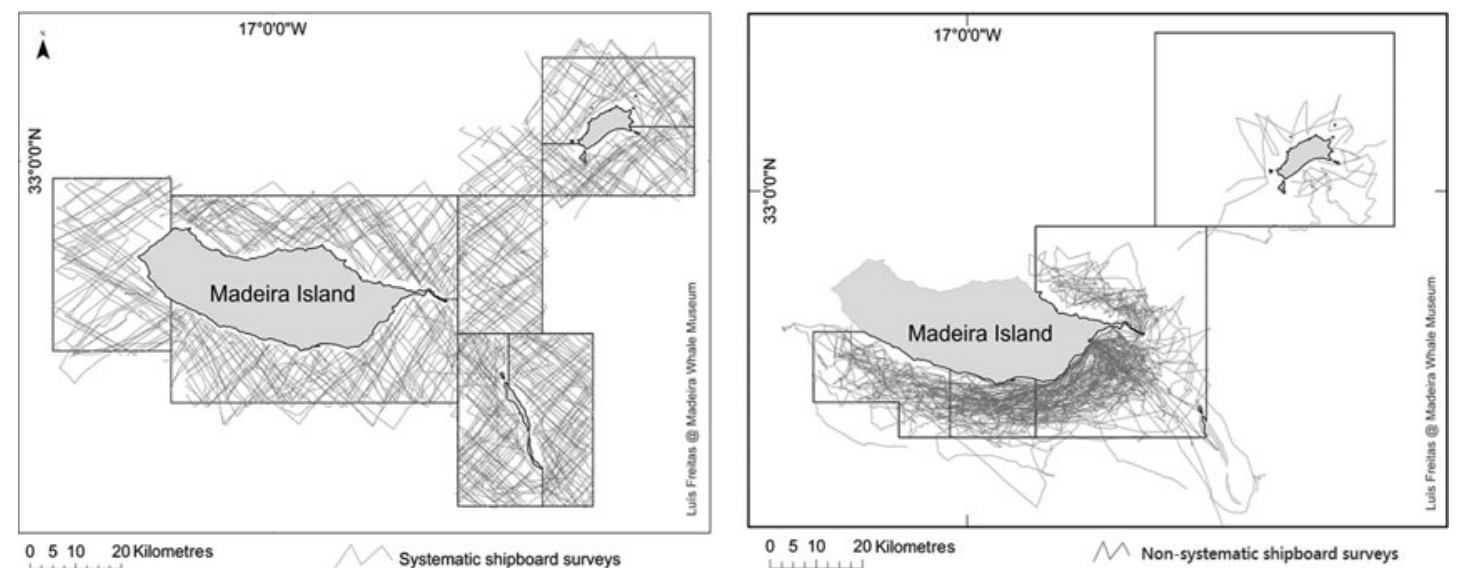

Fig. 2. Maps of survey effort within the study area from 2001-2012: systematic surveys (left); non-systematic surveys (right).

Photographs were graded as 'good', 'fair' or 'bad', according to their level of focus, contrast, exposure, the angle and size of the dorsal fin in the frame. Additionally, the distinctiveness of each photograph was graded as 'very distinct', 'distinct', slightly distinct' or 'unmarked'. All photo processing was done using Darwin 2.0 (C) (Eckerd College Dolphin Research Group), including cropping the dorsal fin area and adjusting light and contrast. Then a contour was drawn to the trailing edge, which is identifiable from both sides (Auger-Méthé \& Whitehead, 2007), and the program compared that fin to all others stored in the database searching for a match. Only the contour was used to compare the fins; secondary features such as fin shape or scars were only used to confirm a match by naked eye. Whenever a match was found, confirmation by the researcher was made by eye, and the same identification number from the individual stored in the database was assigned. If the program did not find a match, the researcher would make another attempt of comparison by eye, with all the individuals of the catalogue, using the number of nicks on the dorsal fin. If a match still was not found, a new identification number was attributed to the individual and it was added to the catalogue. At the end all matches were confirmed by a second experienced researcher. Only good quality photographs and very distinct or distinct individuals were used in this study, in order to enhance the reliability of matches. Calves were excluded from the photo-id analysis. The proportion of well-marked individuals within groups was estimated by using good quality images showing 3-7 individuals $(\mathrm{N}=60)$ in each image, and dividing the well-marked individuals by the total number of photographed individuals in the same image.

\section{Association patterns}

Data for association analysis was organized to suit the needs of the software SOCPROG 2.4 (Whitehead, 2009). Sampling period was defined as a day in order to reduce the bias (Whitehead, 2008) and associations defined as individuals grouped within an encounter with a group of bottlenose dolphins (sighting) (Whitehead \& Dufault, 1999).

\section{CLUSTER ANALYSIS}

Association indices like the simple ratio index (SR) (Ginsberg \& Young, 1992) and the half-weight index (HWI) (Cairns \& Schwäger, 1987) estimate the proportion of time that pairs of individuals are associated (Whitehead, 2008). The index most commonly used in the analysis of social structure in cetacean populations is the HWI (Wells et al., 1987; Smolker et al., 1992; Slooten et al., 1993; Bedjer et al., 1998; Maze-Foley \& Würsig, 2002). This is mainly because in photo-id it is not always possible to photograph and identify all individuals within a group, making the HWI least biased when pairs are more likely to be seen separate than together (Cairns \& Schwäger, 1987). Despite this, Ginsberg \& Young (1992) argued that the general use of the SR is recommended and Whitehead (2008) refers that, if association indices are compared among dyads or within populations it is more likely that the bias will be similar for all dyads, making it of least concern. The cophenetic correlation coefficient (CCC) was used to determine which type of cluster analysis was more suitable to the data. The CCC is the correlation between the actual indices of association and the levels of clustering shown in the diagram and it indicates the effectiveness of the analysis in order to separate potential dendrograms from those that are truly representative of complex social structure. A hierarchical cluster analysis was used to illustrate the relationships between dolphins. For this, only dolphins seen in associations and that had been recorded at least three times between 2001 and 2012 were used. This set of data was selected as appropriate to ensure a more accurate representation, given the range of the existing dataset. The average-linkage method using SR association indices was elected as the most appropriate when compared to single-, complete- and Ward's- linkage methods (not shown). Given that the SR provided the best CCC value, above the value that is considered to be a good fit ( $\geq 0.8$ ) (Bridge, 1993), this index was chosen over the HWI.

Permutation tests were performed to assess if the dolphins showed any preferred/avoided associations, the null hypothesis being that individuals associate randomly. For the null hypothesis to be rejected, the distribution of association indices from the real data should be different from the distribution of association indices from a number of permuted datasets (Whitehead, 2008). Observed SD and CV of the pairwise association indices that were significantly higher than those from permuted datasets were taken as evidence that individuals preferred or avoided companions (Whitehead, 1999).

The number of permutations implemented was increased until the $P$ value obtained from the Monte Carlo simulation stabilized and the confidence intervals decreased (Manly, 
1995; Bedjer et al., 1998; Whitehead, 1999). Two options for permuting data in this kind of analysis were used in this study, to test for both long- and short-term associations: 'Permuting groups within samples' and 'Permuting associations within samples'. The former investigates both short-term (within a sampling period) and long-term (between sampling periods) associations, while the latter investigates only for long-term associations (Whitehead, 2008, 2009). The same author suggested that 'Permuting associations within samples' is the more useful method because it has fewer assumptions and it controls for gregariousness although not for factors affecting the presence of group members (e.g. demographic effects like birth, mortality or migration).

In order to identify significant divisions within the population, modularity (Newman, 2004) was investigated. Modularity is the difference between the proportion of the total association and the expected proportion, within the clusters. It ranges between 0.0 (randomly formed clusters) and 1.0 (no associations between members of different clusters) (Whitehead, 2008). Newman (2004) suggests that if modularity is greater than 0.3 , then the division between the clusters is 'good'. Modularity-G (Whitehead, 2008, 2009) was used as it controls for differences in gregariousness.

\section{TEMPORAL ANALYSES: STANDARDIZED LAGGED}

\section{ASSOCIATION RATE (SLAR)}

We used the Standardized Lagged Association Rate (SLAR) to assess the probability that two individuals associated at a given time, will still be associated at a certain time lag in the future. SLARs are plotted continuously against time lag, with a moving average method. The number of potential associations can be changed, over which the lagged associated rate and its accompanying lag are calculated. Care must be taken to find an optimal moving average that does not compromise the data, because lag will be less precise as the lagged association curve smoothes.

Like other social measures, SLARs have little value without some measures of precision. In this study a temporal jacknife was used, in which different sets of sampling periods are omitted in turn (Whitehead, 2007), and implemented by SOCPROG 2.4. Jackknifing is an acceptable measure of precision even though its estimates are conservative and the assumption of independence might not be met (Whitehead, 1995, 2007). The inclusion of a null model provides an important basis for comparison to determine whether preferred associations are present in the population. It helps to consider what the values would be if the dolphins associated randomly. The standardized null association rate is the inverse of the number of identified individuals minus one, and does not change over time lag (Whitehead, 2008).

Exponential models available in SOCPROG 2.4 were fitted to the SLAR using maximum likelihood and binomial loss. All SLAR models were fitted to the curve and the best-fit model was chosen as that with the lowest Quasi Akaike Information Criteria (QAIC) value following Burnham \& Anderson (2002).

Data from 2004 to 2012 were used to access the temporal pattern of the social structure and comprised all sighting histories independently of the number of times sighted. This is mainly because the SLAR is meant to describe temporal associations between the entire population, and not just those

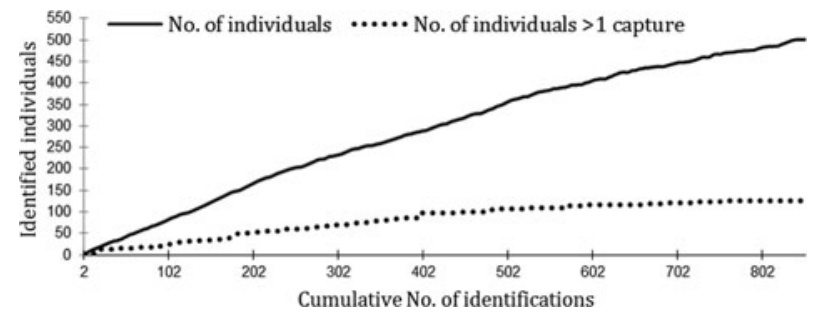

Fig. 3. Discovery curve of the total number of marked individual dolphins (solid line) and the total number of individuals captured $>_{1}$ time (dotted line).

associations within the individuals encountered more often (Whitehead, 2008). Additionally, given the small sample size, the proportion of the group photographed in each sampling period was not a restricting factor in order not to bias the SLAR analyses.

\section{RESULTS}

\section{Photo-identification surveys}

Between 2001 and 2012, there were 272 encounters occurring in 231 different sampling days; these included both dedicated effort and opportunistic whale-watching trips. Individual sighting histories varied greatly during the entire study period, ranging from individuals sighted only once to individuals seen up to 13 times $($ median $=2$ ). A total of 501 individuals were identified and catalogued, based on the marks of their dorsal fin. The discovery curve for the overall number of individuals increased throughout the study period as new individuals kept being added to the catalogue. This result suggests an open population with regular recruitment of new animals to the study area. On the contrary, the discovery curve for re-sighted individuals seemed to stabilize, as less previously identified individuals were being added to the catalogue (Figure 3). After applying constraints for photographic quality and individual distinctiveness, the sample used in the analysis was restricted to 301 individuals. The proportion of well-marked individuals within the groups was estimated to be $68 \%$.

\section{Association patterns}

Seventy dolphins were captured on three or more occasions. The overall mean association index was 0.03 (range $=0.01-$ 0.06; SD \pm 0.01 ) suggesting that, in general, associations within the population were low. Also, the maximum association index for each individual had a low average of 0.38 (range $=0.17-1.00 ; \mathrm{SD} \pm 0.18$ ). The maximum association index of 1.00 was recorded for just two individuals (Tto74 and Tto78) that showed a strong dyadic association (Figure 4).

Permutation tests for non-random associations indicated that in general, the dolphins recorded in this study did not associate preferentially with, nor avoided other individuals. Higher SD and CV values of the real data over the permuted data were non-significant, for both permuted tests (short-term and long term associations) (not shown). As such, the null hypothesis that individuals associate randomly was not rejected. The permutation test supported these findings, given that no dyads were seen to be significantly different from the permuted data. 


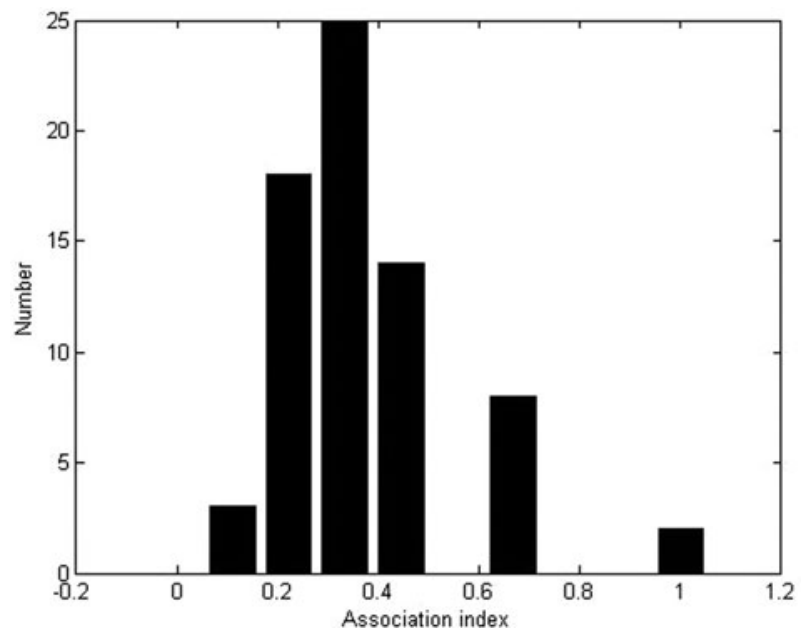

Fig. 4. Distribution of the maximum association index for distinctive individuals, captured $\geq 3$ times in the study area.

\section{CLUSTER ANALYSIS}

The dendrogram produced (Figure 5) was considered representative of the structure within the studied population $(\mathrm{CCC}=0.806)$. All individuals were found to be associated at an association index of $<0.05$. Modularity-G (peak at 0.477 ) suggest that the best community division is at association index (AI) of 0.023 . Applying the variable stopping rule at $\mathrm{AI}$ with maximum modularity value to the dendrogram, resulted in a rapid agglomeration of observed dyads, triads and their multiple networks, from which it becomes impossible to distinguish separate groups. There is no evidence that large groups or clusters forming a significant level of organization exist and much of the division within this population is based on different patterns of identification, rather than preferential companionships. However there was a dyad of dolphins that was always seen together (ID Tto74 and
Tto78; $\mathrm{AI}=1 ; \mathrm{N}=3$ times) and some dyads of dolphins spend more time together than with other individuals. Those dyads refer to dolphins Tt241-Tt245; Tt314-Tt344; Tt16o-Tt271 and Tto56-Tto84 with an AI of 0.67. This hierarchical cluster analysis indicates that the level of fidelity and companionship within this population is low.

\section{TEMPORAL ANALYSES: STANDARDIZED LAGGED ASSOCIATION RATE (SLAR)}

A total of 291 individuals recorded during 108 encounters, corresponding to 101 days, from 2004 to 2012 were used to assess the temporal pattern of the social structure.

The model fit to the SLAR that best described this bottlenose dolphin population was 'casual acquaintances' (Whitehead, 1995) (Table 1; Figure 6). An analysis of the rates of associations between individuals over time showed that the SLAR line starts to decrease at $\sim 500$ days and reaches the null rate confirming the presence of random associations given by the permutation tests made in the cluster analysis. The associations were estimated to last for 998 days (2.7 years) (Figure 6). The social-system model that best fits the SLAR curve indicates casual acquaintances in a large population, possibly including rapid disassociations. However, a second model also strongly supported the SLAR $(\Delta \mathrm{QAIC}=1.60)$ and it suggests two levels of acquaintances: a short, casual level of association and a longer-term, as described by Whitehead (2008). A visual inspection of the data used to generate the SLAR indicates that a small number of individuals seem to have longer associations. For example individuals Tto74 and Tto 8 were seen together twice in the same year (2005) and once 5 years later $(2010)(A I=1)$. Eight individuals (Tto56; Tto84; Tt160; Tt241; Tt245; Tt271; $\mathrm{Tt}_{314}$ and $\mathrm{Tt}_{344}$ ) had an association index of 0.67 , which indicates that for more than $30 \%$ of the time they were seen associated with the same individual. However, when using LARs or SLARs to address the temporal nature of relationships it is

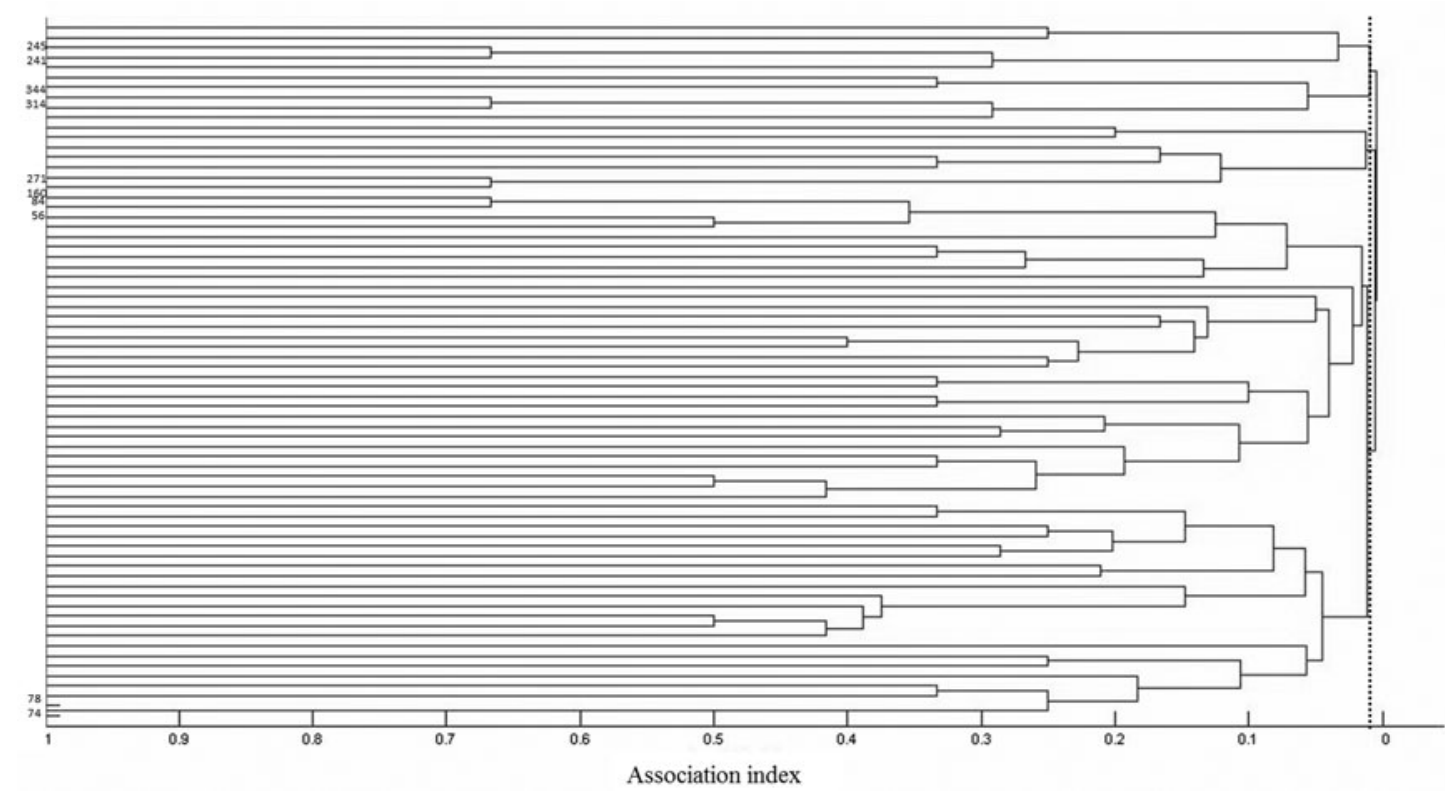

Fig. 5. Dendrogram of bottlenose dolphins in Madeira archipelago using hierarchical cluster analysis. The average linkage and the Simple Ratio Index for association for individuals seen $\geq 3$ times from 2001-2012 is shown. The dotted line represents cluster division resulting from Modularity-G method. The dyads with $\mathrm{AI} \geq 0.67$ are represented by their ID numbers on the $Y$ axis. 
Table 1. Exponential models using maximum likelihood and binomial loss, used to describe the temporal pattern of associations of bottlenose dolphins in Madeira. The best model corresponds to that with lower $\Delta$ QAIC value (highlighted in bold).

\begin{tabular}{|c|c|c|c|c|c|}
\hline Model & Best fit & No Parameters & QAIC & $\Delta Q A I C$ & Support \\
\hline Constant Companions (CC) & $\mathrm{g}^{\prime}=0.009094$ & 1 & 1000.89 & 14.51 & No support \\
\hline Casual Acquaintances (CA) & $\mathbf{g}^{\prime}=0.014543 \times \mathrm{e}^{-0.0010022 \tau}$ & 2 & 986.38 & o & Best support \\
\hline $\mathrm{CC}+\mathrm{CA}$ & $\mathrm{g}^{\prime}=0.0088741+0.2867 \times \mathrm{e}^{-0.57626 \tau}$ & 3 & 998.80 & 12.42 & No support \\
\hline Two levels of CA & $\mathrm{g}^{\prime}=1.3895 \times \mathrm{e}^{-14476 \tau}+0.014029 \times \mathrm{e}^{-0.00095305 \tau}$ & 4 & 987.98 & 1.60 & Strong support \\
\hline
\end{tabular}

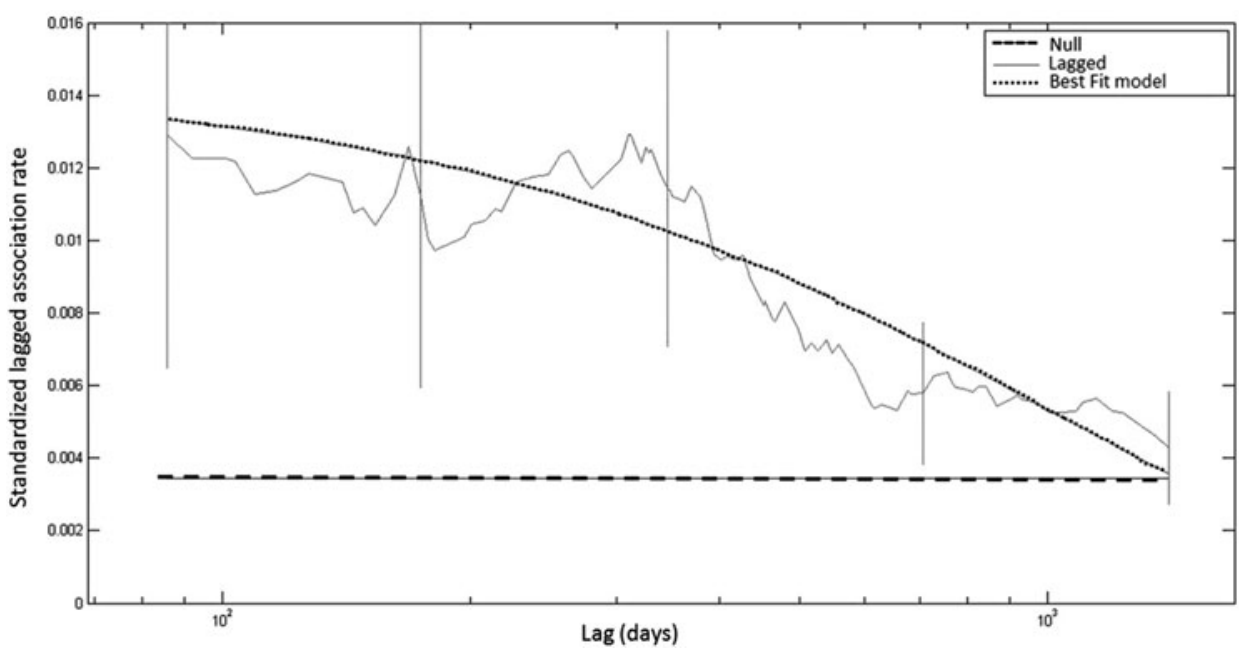

Fig. 6. SLAR for bottlenose dolphins captured between 2004-2012 using a moving average of 3000 associations. Estimated SE bars were produced by jackknifing on each sampling period. The best-fit model suggests casual acquaintances and was obtained using maximum likelihood methods. The null association rate represents the expected value of the SLAR if there was no preferred association and is included for reference.

important to make sure the results are consistent with those obtained through other methods like cluster analysis (Whitehead, 2008). Hence, in accordance with the results obtained by the cluster analysis that showed an overall low association index, the model that uses casual acquaintances to explain social structure in this population was chosen despite some slight variation in association patterns between the individuals used in this analysis.

\section{DISCUSSIDN}

\section{Photo-identification}

There is strong evidence that bottlenose dolphins occurring in the archipelago of Madeira belong to an open population with regular recruitment of new animals to the area. The discovery curve for new individuals does not seem to stabilize, and thus more new individuals are expected to be captured. The large size of the study area may have contributed to this high number of catalogued individuals. Extending the survey area to all three islands (Madeira, Desertas and Porto Santo) allowed a higher chance of capturing transients or dolphins from other communities, as mentioned by Silva et al. (2008) referring to the archipelago of Azores. Nonetheless, the curve of the number of animals with more than one capture (recaptures) seems to be reaching a plateau in the last year of the study. This means that there might not be many more individuals with a strong site-fidelity available to be captured in the study area, as well as that their number is low compared with the number of dolphins in the catalogue. The variations in the time gap between many of the re-sightings of identified individuals in the study area suggested that the Madeira archipelago represents part of a larger home range within the North-east Atlantic. A genetic study by Louis et al. (2014), investigating habitat driven population structure of bottlenose dolphins within the North-east Atlantic, found that individuals sampled in Azores were part of the same population (i.e. shared the same genetic structure) as individuals identified in the European continental shelf, despite the large distance that separate those two places. The lack of genetic differentiation between bottlenose dolphins' populations of Madeira and Azores (Quérouil et al., 2007) supports a similar scenario occurring in the present study, with a small percentage of individuals showing some degree of residency and the majority of the individuals being transients or migrants that move in a much wider area than the study area.

\section{Association patterns}

The results from the dendrogram showed that the overall association index of the dolphins was low and that there was no clear structure in the social organization. The dolphin population presented a dynamic and fluctuating social structure. Given the pelagic nature of the marine environment of Madeira archipelago, this finding is not 
unexpected. Highs level of associations in bottlenose dolphin populations seems to be more common in more enclosed environments, such as estuaries, bays and fjords (Lusseau et al., 2003). The high association levels in more enclosed communities could be partially due to the topographic features that could pose difficulties for neighbouring communities to meet (Lusseau et al., 2003; Merriman, 2007). Nonetheless, this scenario does not apply to an open oceanic habitat. Despite the low AI found in this study, there were two dolphins that were never seen apart and several others that revealed a higher AI than the overall mean, suggesting longer-term relationships. Some stable associations among pairs or even trios of individuals have been documented in various populations of bottlenose dolphins, although there appears to be considerable variability among populations in the types and degree of such stables associations (Connor et al., 2000).

Gender seems to be an important feature driving these associations, as sex-specific bonds are reported for this species in some long-term studies (Connor et al., 2000). The same authors point out that determining the sex of bottlenose dolphins in the field is difficult given the lack of dimorphism in adults. Often sex determination is limited to individuals presumed to be females because of the consistent proximity of a small calf. That was the case in this study, only a few individuals were assumed to be females, although such estimations were not used here.

Prey type may also play an important role in shaping school size and in the decision making with regard to leaving or joining schools, as suggested by Lusseau et al. (2004). Bottlenose dolphins are often reported to circle around fish schools, with one or a few individuals at a time preying on the fishes (Connor et al., 2000). The Madeira archipelago is an open water habitat allowing bottlenose dolphins to pursue schooling as well as pelagic solitary prey throughout the water column.

The results of the permutation test did not lead to the rejection of the null hypothesis, suggesting that random associations persist in the bottlenose dolphins population studied in Madeira. Similarly, the temporal analysis also indicated the presence of random associations over time. The decline of the SLAR curve after $\sim 500$ days (1.4 years) suggests disassociation over that time period which can be explained by demographic events such as mortality or emigration (Whitehead, 2008). However, the associated SEs on the SLAR are quite large, so it should be noted that these are general trends that cannot predict the association pattern of all individuals at all times.

A study carried out on bottlenose dolphins in the outer Moray Firth (Eisfield \& Robinson, 2004) obtained similar results to those presented here. The authors found no clear architecture or division of groups except for dyads and triads with random associations. Identical results were found in the Shannon Estuary, Ireland, where social structure in a smaller population of dolphins was found to be highly fluid, within which individuals change their composition and associates regularly (Foley et al., 2010). Similarly, focal follows studies in Shark Bay, Australia describe changes in group composition occurring on average three or four times per hour (Connor et al., 2000). More uncommon perhaps in this species are the results of Lusseau et al. (2003) (Doubtful Sound, New Zealand) and Augusto et al. (2012) (Sado Estuary, Portugal) that demonstrated a unique fission-fusion social structure, as long lasting associations were a strong feature of these communities.

To summarize, bottlenose dolphin social structure can vary drastically, from being mainly driven by constant companionship to featuring mostly acquaintances that last only a few days (Lusseau et al., 2006). It would be useful to examine if different segments of the populations show different patterns of interactions, like sex-related relationships. That would be interesting future research in this population present in Madeira.

It is important to highlight that the association indices reported here can be negatively biased, mostly due to the inherent difficulties of the methodology applied (Stevick et al., 2001); those difficulties lie mainly in the inability to photograph each individual present during each encounter. In addition, as the study was restricted only to well-marked individuals. Potential associations between unmarked individuals (like calves and juveniles) and the rest of the population is not being accounted for. Mother/calf pairs of bottlenose dolphins living in a fission-fusion community are expected to present long-term associations as calves are known to stay with their mother for up to 8 years after birth (Greiller et al., 2003).

In conclusion, this population exhibits a fission-fusion society predominantly formed of short-term acquaintances with only a few long-lasting associations, apparently similar to more coastal communities of bottlenose dolphins like the ones in Sarasota Bay, Florida (Wells et al., 1987) or in the Scottish east coast (Lusseau et al., 2006). Understanding the social relationships among individuals is important to define management guidelines for this population of bottlenose dolphins in Madeira.

\section{ACKNDWLEDGEMENTS}

We wish to thank João Viveiros, Miguel Silva, Hugo Vieira, Filipe Nóbrega, Ana Higueras, Nuno Marques, Marianne Böhm-Beck, Jonatan Svensson, Virginie Wyss, Daniel Martins and Mafalda Ferro for fieldwork assistance; Carlos Silva, Rita Ferreira, Luís Dias, Raquel Marques, Claudia Gomes and Rafael Gomes who contributed with photographs. We thank Manuel E. Dos Santos and one anonymous reviewer for helpful comments on the manuscript.

\section{FINANCIAL SUPPORT}

This work was carried out by the Madeira Whale Museum and funded by the Município de Machico, LIFE and FEDER/ INTERREG III-B EU programs, during projects CETACEOS MADEIRA (LIFE99 NAT/P/o06432), MACETUS (MAC/ 4.2/M10), EMECETUS (05/MAC/4.2/M10) and CETACEOS MADEIRA II (LIFE+ NAT/P/ 000646); and by the Portuguese Foundation for Science and Technology (FCT), project GOLFINICHO (POCI/BIA-BDE/61009/2004). Recent re-analysis, final write up and revision phases carried out by the first author had the support of a post-doc grant from ARDITI - Madeira's Regional Agency for the Development of Research, Technology and Innovation, project M1420-095369-FSE-000001.

\section{REFERENCES}

Alves F., Querouil S., Dinis A., Nicolau C., Ribeiro C., Freitas L., Kaufmann M. and Fortuna C. (2013) Population structure of shortfinned pilot whales in the oceanic archipelago of Madeira based on 
photo-identification and genetic analyses: implications for conservation. Aquatic Conservation: Marine and Freshwater Ecosystems 5, $758-776$.

Auger-Méthé M. and Whitehead H. (2007) The use of natural markings in studies of long-finned pilot whale (Globicephala melas). Marine Mammal Science 23, 77-93.

Augusto J.F., Rachinas-Lopes P. and dos Santos M.E. (2012) Social structure of the declining resident community of common bottlenose dolphins in the Sado Estuary, Portugal. Journal of the Marine Biological Association of the United Kingdom 92, 1773-1782.

Bedjer L., Fletcher D. and Bräger S. (1998) A method for testing association patterns of social animals. Animal Behaviour 56, 719-725.

Bridge P. (1993) Classification. In Fry J. (ed.) Biological data analysis: a practical approach. New York, NY: Oxford University Press, pp. 219-242.

Burnham K.P. and Anderson D.R. (2002) Model selection and multimodel inference: a practical information-theoretic approach. New York, NY: Springer-Verlag.

Cairns S.J. and Schwäger S.J. (1987) A comparison of association indices. Animal Behaviour 35, 1454-1469.

Caldeira R. and Sangrá P. (2012) Complex geophysical wake flows: Madeira Archipelago case study. Ocean Dynamics 62, 683-700.

Connor R., Wells R., Mann J. and Read A. (2000) The bottlenose dolphin: social relationships in a fission-fusion society. In Mann J., Connor R., Tyack P.L. and Whitehead H. (eds) Cetacean societies: field studies of dolphins and whales. Chicago, IL: University of Chicago Press, pp. 91-126.

Costa J. and Fitzgerald T. (1996) Developments in social terminology: semantics battles in a conceptual war. Trends in Ecology Evolution $11,285-289$.

Eisfield S. and Robinson K. (2004) The sociality of bottlenose dolphins in the outer Moray Firth NE Scotland: implications for current management proposals. Proceedings of the 18th Annual Conference of the European Cetacean Society, Kolmården, Sweden, 28-31 March.

Foley A., MacGrath D., Berrow S. and Gerristsen H. (2010) Social structure within the bottlenose dolphin (Tursiops truncatus) population in the Shannon Estuary, Ireland. Aquatic Mammals 36, 372-381.

Geldmacher J., Van Den Bogaard P., Hoernle K. and Schmincke H. (2000) The 40Ar/39Ar age dating of the Madeira Archipelago and hotspot track (eastern North Atlantic). Geochemistry Geophysics Geosystems 1, 1999GCoooo18.

Ginsberg J.R. and Young T.P. (1992) Measuring association between individuals or groups in behavioural studies. Animal Behaviour 44, 377-379.

Greiller S., Hammond P.S., Wilson B., Sanders-Reed C.A. and Thompson P.M. (2003) Use of photo-identification data to quantify mother-calf association patterns in bottlenose dolphins. Canadian Journal of Zoology 81, 1421-1427.

Hoelzel A., Potter C. and Best P. (1998) Genetic differentiation between parapatric 'nearshore' and 'offshore populations of the bottlenose dolphin. Proceedings of the Royal Society Series B, Biological Sciences $265,1177-1183$.

Louis M., Viricel A., Luca T., Peltier H., Alfonsi E., Berrow S., Brownlow A., Covelo P., Dabin W., Deaville R., de Stephanis R., Gally F., Gauffier P., Penrose R., Silva M.A., Guinet C. and Simon-Bouhet B. (2014) Habitat-driven population structure of bottlenose dolphins, Tursiops truncatus, in the North-East Atlantic. Molecular Ecology 23, 857-874.

Lusseau D., Schneider K., Boisseau O.J., Haase P., Slooten E. and Dawson S. (2003) The bottlenose dolphin community of Doubtful
Sound features a large porportion of long-lasting associations: can geographic isolation explain this unique trait? Behavioral Ecology and Sociobiology 54, 396-405.

Lusseau D., Williams R.J., Wilson B., Grellier K., Barton T.R., Hammond P.S. and Thompson P.M. (2004) Parallel influence of climate on the behaviour of Pacific killer whales and Atlantic bottlenose dolphins. Ecology Letters 7, 1068-1076.

Lusseau D., Wilson B., Hammond P.S., Grellier K., Durban J.W., Parsons K.M., Barton T.R. and Thompson P.M. (2006) Quantifying the influence of sociality on population structure in bottlenose dolphins. Journal of Animal Ecology 75, 14-24.

Manly B. (1995) A note on the analysis of species co-occurrences. Ecology $76,1109-1115$.

Mann J., Connor R.C.L., Barre M. and Heithaus M.R. (2000) Female reproductive success in bottlenose dolphins (Tursiops sp.): life history, habitat, provisioning, and group-size effects. Behavioral Ecology 11, 210-219.

Maze-Foley K. and Würsig B. (2002) Patterns of social affiliation and group composition for bottlenose dolphins (Tursiops truncatus) in San Luis Pass, Texas. Gulf of Mexico Science 20, 122-134.

Merriman M.G. (2007) Abundance and behavioural ecology of bottlenose dolphins (Tursiops truncatus) in the Marlborough Sounds, New Zealand. Master's thesis, Massey University, New Zealand.

Newman M. (2004) Analysis of weighted networks. Physical Review E70, 056131.

Quérouil S., Silva M.A., Freitas L., Prieto R., Magalhães S., Dinis A., Alves F., Matos J.A., Mendonça D., Hammond P. and Santos R.S. (2007) High gene flow in oceanic bottlenose dolphins (Tursiops truncatus) of the North Atlantic. Conservation Genetics 8, 1405-1419.

Silva M.A., Prieto R., Magalhães S., Seabra M.I., Santos R.S. and Hammond P.S. (2008) Ranging patterns of bottlenose dolphins living in oceanic waters: implications for population structure. Marine Biology 179, 179-192.

Slooten E., Dawson S.M. and Whitehead H. (1993) Associations among photographically identified Hector's dolphins. Canadian Journal of Zoology 71, 1311-1328.

Smolker R., Richards A., Connor R.C. and Pepper J.W. (1992) Sex differences in patterns of association among Indian Ocean bottlenose dolphins. Behaviour 123, 38-69.

Stevick P.T., Palsbøll P.J., Smith T.D., Bravington M.V. and Hammond P.S. (2001) Errors in identification using natural markings: rates, sources, and effects on capture-recapture estimates of abundance. Canadian Journal of Fisheries and Aquatic Science 58, 1861-1870.

Wells R. (1991) The role of long-term study in understanding the social structure of a bottlenose dolphin community. In Pryor K. and Norris K. (eds) Dolphin societies: discoveries and puzzles. Berkeley, CA: University of California Press, pp. 199-225.

Wells R. (1986) Population structure of bottlenose dolphins along the central west coast of Florida. Southeast Fisheries Center: Contract Report to National Marine Fisheries Service.

Wells R., Rhinehart H., Cunningham P., Whaley J., Baran M., Koberna C. and Costa D. (1999) Long distance offshore movements of bottlenose dolphins. Marine Mammal Science 15, 1098 - 1114.

Wells R., Scott M., Irvine A. (1987) The social structure of free-ranging bottlenose dolphins. In Genoways H. (ed.) Current mammalogy. New York, NY: Plenum Press, pp. 247-305.

Whitehead H. (1995) Investigating structure and temporal scale in social organizations using identified individuals. Behavior Ecology 6, 199208. 
Whitehead H. (1999) Testing association patterns of social animals Animal Behaviour 57, 26-29.

Whitehead H. (2007) Selection of models of lagged identification rates and lagged association rates using AIC and QAIC. Communication in Statistics - Simulation and Computation 36, 1233-1246.

Whitehead H. (2008) Analyzing animal societies: quantitative methods for vertebrate social analysis. Chicago, IL: University of Chicago Press.

Whitehead H. (2009) SOCPROG programs: analysing animal social structures. Behavioral Ecology and Sociobiology 63, 765-778.

Whitehead H. and Dufault S. (1999) Techniques for analysing vertebrate social structure using identified individuals: review and recommendations. Advances in the Study of Behavior 28, 33-74.

Whitehead H. and Van Parijs S. (2010) Studying marine mammal socia systems. In Boyd I., Don Bowen W. and Iverson S. (eds) Marine mammal ecology and conservation: a handbook of techniques. New York, NY: Oxford University Press, pp. 263-282.

Wilson D. (1995) The ecology of bottlenose dolphins in the Moray Firth, Scotland: a population at the northern extreme of the species' range. $\mathrm{PhD}$ thesis, Aberdeen University, Aberdeen, Scotland.
Wilson E.O. (1975) Sociobiology: the new synthesis. Cambridge, MA: Belknap Press.

Würsig B. and Jefferson T. (1990) Methods of photo-identification for small cetaceans. In Hammond P.S., Mizroch S.A. and Donovan G.P. (eds) Individual recognition of cetaceans: use of photo-identification and other techniques to estimate population parameters. Report of the International Whaling Commission, special issue 12. Cambridge: International Whaling Commission, pp. 43-52.

and

Würsig B. and Würsig M. (1977) The photographic determination of group size, composition and stability of coastal porpoises (Tursiops truncatus). Science 198, 755-756.

\section{Correspondence should be addressed to:}

A. Dinis

Madeira Whale Museum, Caniçal, Madeira, Portugal email: ana.dinis@ciimarmadeira.org 